\title{
A Review on the New Trends of Acrylamide Toxicity
}

\author{
Ahmed Ghamdi ${ }^{1}$, Fahad Alenezi ${ }^{1}$, Misfer Algoferi ${ }^{1}$, Mohamed Alhawas ${ }^{1}$, Ammar AL Farga $^{2}$ and \\ Mohamed Afifi ${ }^{2 *}$ \\ ${ }^{1}$ College of Applied Medical Sciences, Kingdom of Saudi Arabia \\ ${ }^{2}$ Department of Biochemistry, College of Science, Saudi Arabia
}

*Corresponding author: Mohamed Afifi, University of Jeddah, College of Science, Department of Biochemistry, Jeddah, Saudi Arabia, P.O. Box 80203, Jeddah 21589, Saudi Arabia

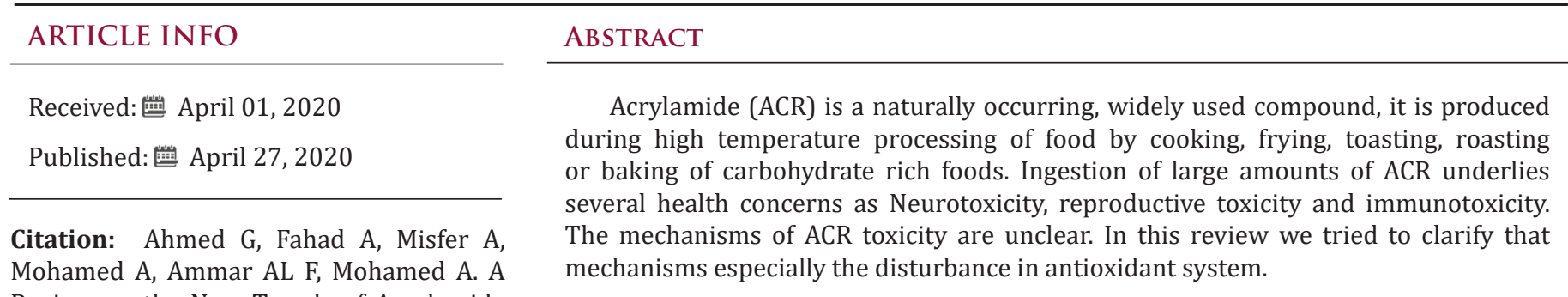

Review on the New Trends of Acrylamide

Toxicity. Biomed J Sci \& Tech Res 27(2)-

Keywords: Acrylamid; Toxicity; Mechanism 2020. BJSTR. MS.ID.004480.

\section{Introduction}

Acrylamide (ACR) is a chemically colorless and odorless crystalline. It is usually soluble in water and some polar solvent like ethanol, methanol and acetone. This substance is formed during the preparation of some foods at a high temperature of more than 125 degrees Celsius, by roasting for some types of foods that have a high percentage of carbohydrates such as potato chips, toast, etc Zamani et al. [1] It was discovered and classified as pollutants in 2002 by the Swedish National Welfare Food Committee Fang et al. [2] ACR can also be exposed in the environment or workplaces through air and water, and during its production or use, in addition to its presence in adhesives, cosmetics, and graphic films Taeymans et al. [3] Many occupational and environmental problems have been registered from the wide use of ACR which was primarily used as flocculants for clarifying drinking water Granath et al. [4] Indeed, ACR is used mainly in the formation of poly-acrylamides, which are widely used in plastics, paints, varnishes, adhesives and mortar. It is also applied in toiletries and cosmetics Pingot et al. [5]

Naturally, ACR is formed through interaction of amino acids with reducing sugar. This occurs during frying, grilling, baking or roasting carbohydrate rich food as bread, potato crisps, chips crackers and french fries at temperatures above $1200 \mathrm{oC}$. This increased the concern about cancer risks associated with the dietary intake of fried or backed carbohydrate food Tareke et al.
$[6,7]$. It was evident that exposure to large doses of ACR causes damage to male reproductive glands. Adding to this, direct ACR inhalation or skin absorption irritates the exposed tissue and can lead to nausea, sweating, speech disorders, paresthesia, numbness, myalgia, urinary incontinence and paraparesis Alberts et al. [8] As well as, it has a carcinogenic effect in rodents Lo Pachin $[9,10]$ Many of studies showed that ACR is absorbed rapidly and effectively by means of gastrointestinal tract Shipp et al. [11] It passes through the placental barrier in humans and animals, so that, maternal exposure is a relevant measure of the fetal exposure to ACR Schettgen et al. [12] Antioxidants may enhance or inhibit ACR, as the different antioxidants have shown different results. But if they are of an unstable type, they may turn into an oxide form and thus may lead to a reduction of ACR.

\section{Pathways for ACR Synthesis in Food}

Acrylamide (acrylic amide; $\mathrm{CH}_{2}=\mathrm{CHC}(\mathrm{O}) \mathrm{NH}_{2}$ ), an organic compound is a white crystalline odorless solid Front [13] ACR has molecular weight of 71.08 and is soluble in water and many other organic solvents like acetone, methanol and ethanol. It is almost insoluble in nonpolar solvents such as carbon tetrachloride. The boiling point of ACR is $125^{\circ} \mathrm{C}(25 \mathrm{~mm} \mathrm{Hg})$, the melting point is 84.5 ${ }^{\circ} \mathrm{C}$ and the density is $1.27 \mathrm{~g} / \mathrm{ml}\left(25^{\circ} \mathrm{C}\right)$ Hawley and Lewis [14] It is produced as a precursor of polyacrylamides, which is used as 
water-soluble thickeners and flocculating agents in industry. It is mainly used in aqueous solution because of its highly toxic effect, which is likely to be carcinogenic Kumar et al. [15] ACR is formed in food when carbohydrate-rich food processed at high temperatures $\left(>120{ }^{\circ} \mathrm{C}\right.$ ) such as boiling, frying, toasting, roasting and baking (Ankaiah et al. [16] It happens when amino acid asparagine reacts with sugars, especially glucose and fructose, due to the Maillard reaction (Figures 1\& 2) Claus et al. [17] In addition, ACR is not present as a natural source, but it can be produced because of high temperatures when sugars and amino acids react with each other in carbohydrate (and/or protein)-rich foods during the cooking process. Actually, this monomeric compound can be founding a variety of foods such as potato chips, fries, breads, cereals, including coffee like toasting, frying, baking and cooking at high temperature The most important sources are the potato products, coffee, and bakery products. The darker the color of the fried or baked food (e.g. French fries or toast), the higher the ACR contents Krishna Kumar et al. [18].

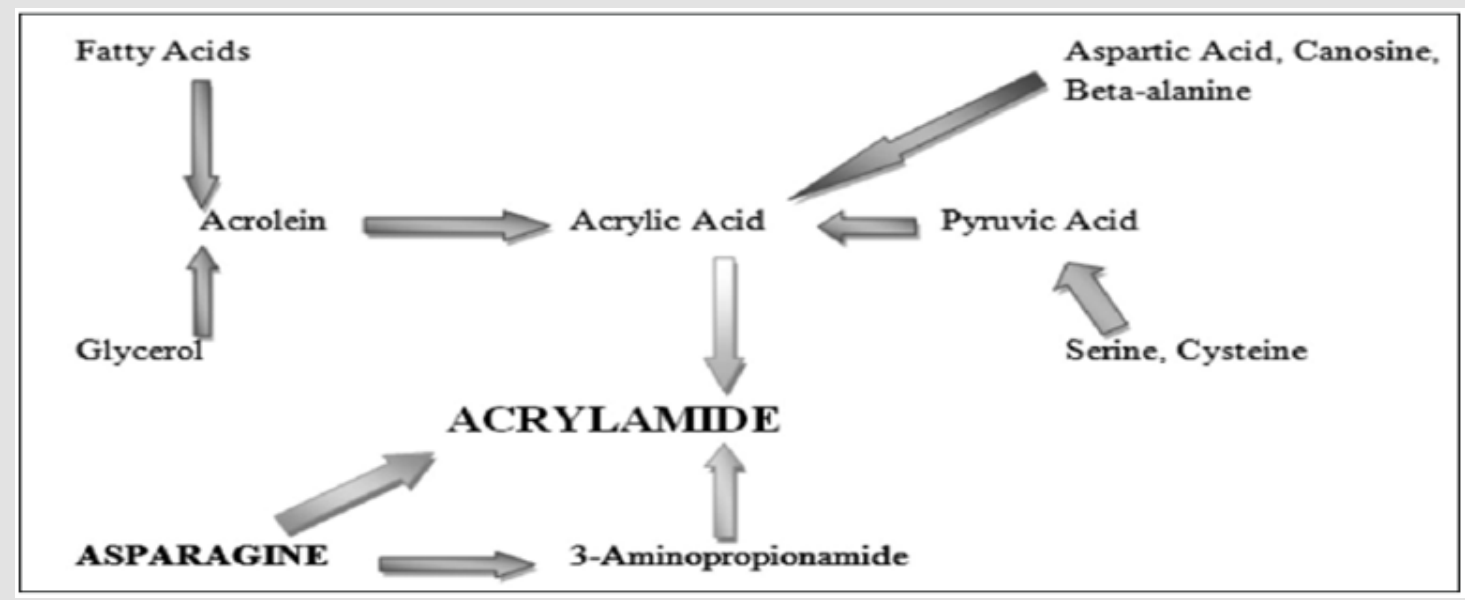

Figure 1: Basic pathways of acrylamide formation in foods Claus et al. [17].

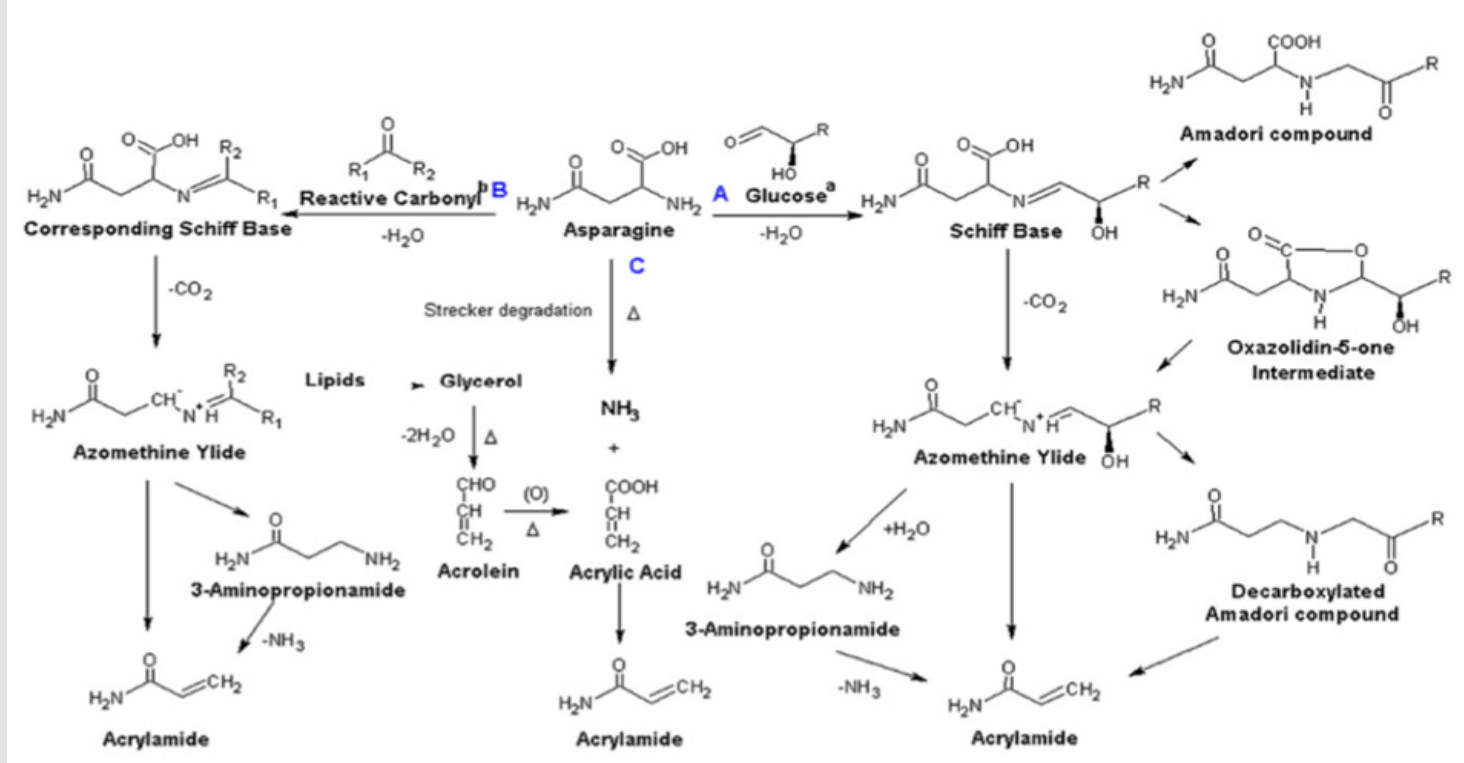

Figure 2: Formation pathways of acrylamide from asparagine. a: a-hydroxy carbonyl compound, take glucose as an example. b:R1 or R2 has an $a, \beta, \gamma, \delta$-diunsaturated carbonyl group or $a$-carbonyl, or R1 or R2=H sometimes Claus et al. [17].

\section{Exposure and Intake of Acrylamide}

The different concentration of ACR in foods were recorded in each country according to national dietary trends and food preparation methods. Direct exposure to ACR typically results from eating high-carbohydrate foods like potato crisps, cookies, roasted cereals, and breads. Food packaging with ACR also contributes to indirect exposure to ACR Zhang et al. [19] Therefore, estimation of the intake of ACR from food items is also a problem in many countries. Potato products is alone account for $50 \%$ of human exposure to ACR based on recorded data. Baking goods and bread make up $20 \%$ of this list. Bakery products, bread and rolls have little ACR but the highest rates were found in the bread crust and there is almost no ACR content is found in the bread crumb Negoita and 
Culetu [20] Potato crisps have the largest levels of ACR (1360 $\mu \mathrm{g} /$ kg; range: $330-2300 \mu \mathrm{g} / \mathrm{kg}$ ) and $540 \mu \mathrm{g} / \mathrm{kg}$ (range: $300-1100 \mu \mathrm{g}$ $/ \mathrm{kg}$ ) for French fries. Adults are estimated to consume a maximum of 0.3 to $0.6 \mu \mathrm{g} / \mathrm{kg}$ / day of ACR while the mean intake of ACR for children is greater $(0.4-0.6 \mu \mathrm{g} / \mathrm{kg})$.

This can be due to intake of high calorie foods in children like french fries and potato crisps Dybing et al. [21] In the US, $38 \%$ of the overall daily intake of energy comes from foods with high levels of ACR. In addition, ACR was found in cigarettes (1-2 $\mu \mathrm{g}$ / cigarette) which caused smoking people to be exposed to higher levels of ACR than non-smokers Petersen et al. [22] Boys and girls aged 13year ingest 0.52 and $0.49 \mu \mathrm{g} / \mathrm{kg} /$ day, respectively. Coffee intake also increases that value to $0.49 \mu \mathrm{g} / \mathrm{kg} /$ day in men and $0.46 \mu \mathrm{g} / \mathrm{kg} /$ day in women. Men consume an average of $0.36 \mu \mathrm{g} / \mathrm{kg} /$ day although this amount is lower for women $(0.33 \mu \mathrm{g} / \mathrm{kg} /$ day $) .16-30$ years old men take highest amount of ACR. Interestingly, the primary sources of ACR consumption were the potato products and coffee Svensson et al. [23] In Sweden adult's average dietary intake of ACR from food products was estimated at around $31 \mu \mathrm{g} /$ day Dybing et al. [24] The average daily consumption of ACR at 7-19 years of age is 0.3 $\mu \mathrm{g} / \mathrm{kg} /$ day and $0.71 \mu \mathrm{g} / \mathrm{kg} /$ day in the Germany and Netherlands respectively. In Brazil, as an example from South American countries the mean intake of ACR from food was estimated to be $0.12 \mu \mathrm{g} / \mathrm{kg}$ / day at the age of 11-17 years. ACR intake for Brazilian adolescents is lower than recorded in European countries. These differences may be due to the use of different food patterns Arisseto et al. [25]

\section{Pharmacokinetic of Acrylamide}

ACR is a small organic molecule with electrophilic vinyl group that can be attacked by nucleophiles. This compound is shown to have a rapid and complete absorption in rats via gastrointestinal track, it also absorbed from skin Zamani et al. [1] Toxicokinetic studies in human showed that ACR has terminal half-life 2.4-7.0 h Matoso et al. [26] Cytochrome P450 2E1 (CYP2E1) can metabolize
ACR leading to the development of an epoxide derivative like glycidamide, which is more reactive to attack to DNA and protein than the parent compound Sumner et al. [27] ACR and glycidamide are conjugated with GSH and then excreted in human urine as by-products of merapturic acid Riboldi et al. [28] In addition, ACR directly react with GSH under the catalysis of hepatic GSHS-transferases Bucur et al. [29] After i.v or oral administration of ACR $(0.5-100 \mathrm{mg} / \mathrm{kg})$, is rapidly distributed across the body. Approximately $12 \%$ stored in RBC for at least 10 days at high concentration this persistence was supposed to result from ACR's reaction with sulfhydryl groups in hemoglobin. The higher percentage of it is found in muscle (48\%), skin (15\%), blood (12\%) and liver (7\%), while the neural tissues like brain, spinal cord, and sciatic nerve has less than $1 \%$ Zhao et al. [30]

\section{Mechanism of Acrylamide Toxicity}

Oxidative stress may occur when there is an imbalance in the ratio of the biological oxidant to the antioxidant. It may also be the initiator step to many other illnesses Mojtahedzadeh et al. [31] In vivo free radicals are continuously produced. The body has defensive barriers such as antioxidant enzymes superoxide dismutase (SOD), catalase, glutathione S-transferase (GST), glutathione peroxidase (GPx) and proteins such as GSH for neutralizing the harmful effects of free radicals Shaki et al. [32] Some studies in recent years have shown that ACR has caused oxidizing stress. It affects the cellular redox chain by production of reactive oxygen (ROS) species. It is oxidized to glycidamide, and then conjugated with GSH. ACR and glycidamide are capable to interact in cells with a group of nucleophiles (such as $-\mathrm{SH},-\mathrm{NH} 2$ or $-\mathrm{OH}$ ). ACR directly react with GSH under the catalysis of hepatic GSH-S-transferases Bucur et al. [29] As the concentration of ACR increases, GST and SOD activity increase and the GSH concentration is decreased Chen et al. [33] It is also reported that ACR can induce apoptosis due to oxidative stress Yilmaz et al. [34] Chronic dietary ACR exposure may induce oxidative stress in humans.

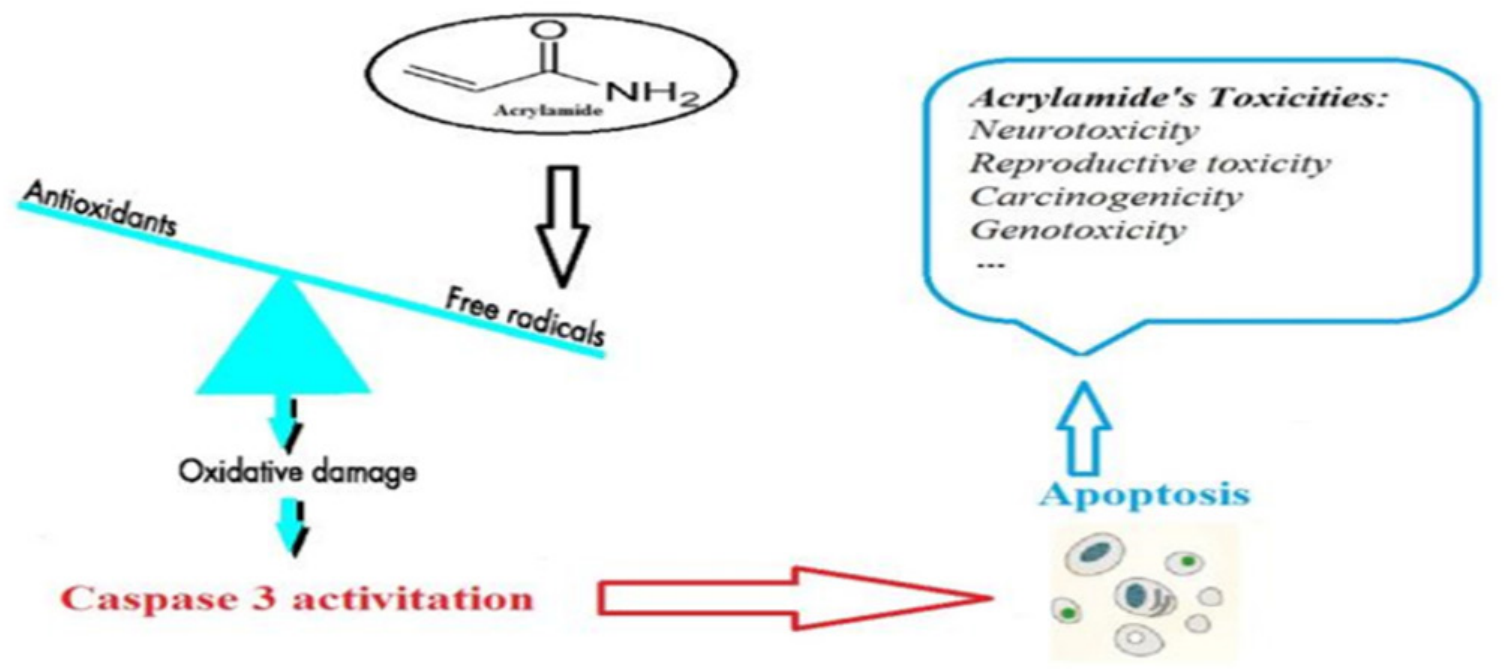

Figure 3: Mechanism of acrylamide's toxicity. 
After exposure to ACRROS formation and GSH oxidation is also increased in isolated human monocyte Naruszewicz etal.[35] (Figure 3). Oxidative stress is an introduction to inducing the most critical form of cell death, including apoptosis. Usually ACR is conjugated with GSH after rapid intestinal absorption non enzymatically and enzymatically which results in reduction of cellular GSH stores Nakagawa et al. [36] Depletion of GSH levels increase levels of ROS which are widely recognized as key cell function mediators. ROS activate the mitogen activated protein kinase (MAPK)-JNKs that play an important role in controlling cellular processes such as apoptosis Valko et al. [37] Multiple studies have shown that cellular glutathione redox deficiency in the intestinal cells is an important factor in apoptotic signaling and cell death. Consequently, reduced rates of GSH result in cellular oxidative stress, and apoptosis may be suggested as a possible mechanism for toxicity with ACR Rodríguez Ramiro et al. [38] Sub chronic exposure to ACR has changed the expression of death-related proteins in CNS and PNS tissue which indicate the early molecular regulatory mechanism of apoptosis in ACR neuropathy Li et al. [39]

In a time-and dose-dependent manner in astrocytic cells, long exposure to ACR at a concentration of $2 \mathrm{mM}$ or greater can cause apoptosis and astrogliotic responses Chen et al. [40] The researchers showed in another study that ACR increases $\mathrm{p} 53$ protein phosphorylation at Ser15 in human neuroblastoma cells (SH-SY5Y) leading to p53 activation Okuno et al. [41] It is evident that p53, as a tumor suppressor gene, plays a major role in the apoptosis of the neurons Morrison et al. [42] In addition, ACR mitigated cell viability in human neuroblastoma cells (SH-SY5Y) in a dose-dependent manner, increased caspase- 3 activity and cell population at a low dose ( $2 \mathrm{mM}$ ), while both were lower at higher doses (4 and $5 \mathrm{mM}$ ) Sumizawa et al. [43] The exposure of BV2 cells (mouse microglia cell line) to ACR showed a concentration-dependent reduction in cell viability and induced apoptosis. Impairment in the respiratory chain of mitochondria, aerobic glycolysis, and decreased expression of complex I, III, and IV subunits result in ACR toxicity was also observed. A decrease in the mitochondrial membrane potential and the $\mathrm{Bcl}-2 / \mathrm{Bax}$ ratio results in activation of apoptotic signals driven by mitochondrion. Increased expression of NFÿB and downstream inducible synthase of nitric oxide (iNOS) and production of nitric oxide indirectly supports a pro-inflammatory effect of ACR. The expression of Nrf2 was also increased but not translocated to the nucleus Liu et al. [44]

\section{ACR Neurotoxicity}

Several studies have concluded that ACR can be considered a potent neurotoxic agent. No-observable adverse effect level (NOAEL) for ACR neurotoxicity in laboratory animals is $0.2-0.5 \mu \mathrm{g}$ / kg / day, and the lowest observed adverse effect level (LOAEL) is $2 \mu \mathrm{g} / \mathrm{kg} /$ day, respectively. ACR neurotoxicity is the only toxic effects that have been observed in both human and animals. Studies in many species of laboratory animals such as cats, rats, mice, guinea pigs, rabbits, and monkeys have shown that prolonged routine exposure to ACR results in triad effects: ataxia, hind-limb foot splay, and skeletal muscle weakness Exon [45] In rat primary astrocytes ACR mediated apoptosis contributes to mitochondrial dysfunction and apoptosis in BV-2 microglial cells Liu et al. [44] Several studies have measured the neurotoxic impact of ACR in the working environment LoPachin et al. [46] For example, during the construction of a railway tunnel near the southwest of Sweden, workers began to show signs of impaired nerve function, as a result of a special gel called Rhoca-Gel containing ACR used for waterproof leakage in the tunnel wall Hagmar et al. [47] In another study it was shown that ACR disturbed the nervous system by inhibiting cellular differentiation of human neuroblastoma and gelioblastoma Chen et al. [40]

\section{Carcinogenicity and Genotoxicity of Acrylamide}

ACR is listed by the International Agency for Research on Cancer (IARC) as "probable human carcinogen" Pelucchi et al. [48] There is no evidence of carcinogenic effects of ACR from epidemiologic research or occupational use in humans. ACR has a similar structure to carcinogenic compounds like vinyl carbamate and acrylonitrile. Nonetheless, prolonging animals exposed to high concentrations in drinking water contributes to the production of multiple tumors in both male and female genera at multiple sites Exon [45] Very much work has demonstrated the carcinogenicity of ACR. Results showed ACR can increase the risk of certain cancers. For example, in postmenopausal women, exposure to ACR was really associated with kidney and breast cancers. Some research however disputes these findings Pelucchi et al. [49] A positive relationship was observed between dietary ACR and renal cell cancer while there is no positive relationship to the risk of bladder and prostate cancer Hogervorst et al. [50] Several studies have investigated the genotoxicity of ACR and its main metabolite, glycidamide. One of the important criteria in determining carcinogenicity is the capacity to generate genetic damage Exon [45] For example, studies have shown that ACR at the 10, 20 and $30 \mathrm{mg} / \mathrm{kg}$ dose significantly induced DNA damage compared to the control group Alzahrani [51] The genotoxic effect of ACR in cell culture was demonstrated in another study by in vitro testing and in vivo animal models Exon [45].

\section{Reproductive Toxicity of Acrylamide}

Reproductive toxicity was also assessed in animals receiving elevated levels of ACR from laboratory. There is no proof for human reproductive toxicity of ACR. The no-observed adverse effect level (NOAEL) for reproductive toxicity in rats was estimated at 2-5 $\mu \mathrm{g} /$ $\mathrm{kg} /$ day. This dose is at least four times higher than the acrylamide neurotoxicity needed by doses and 2000 times higher than expected dietary exposures Tyl et al. [52] Additionally, ACR administration of $0.5-10 \mathrm{mg} / \mathrm{kg}$ retarded rat growth and decreased epididymal sperm reserves compared to control group. In the testis of treated rats, histopathologic lesions were also present Wang et al. [53] In one study, concentrations of testosterone and prolactin decreased 
as a dose-dependence mode after ip injection of ACR doses (20 mg / kg) in male rats Zamani et al. [1] It is revealed in another study that ACR can be detrimental to female reproductive system in mice. They showed that oral doses of ACR significantly decreased body weights, organ weights, and corporal lutea count. ACR decreased concentrations of serum progesterone as dose relied Wei et al. [54]

\section{Immunotoxicity of Acrylamide}

ACR's immunotoxicity has been reported less than its neuro and reproductive toxicities. In a survey ACR immunotoxicity observed in Female BALB / c Mice. In the study it is found that the final body weight, spleen and thymus weights, lymphocyte counts, decreased with ACR. Pathological variations in lymph glands, thymus, and spleen have also been observed. It is also reported that ACRcan substantially decrease T cells and natural killer (NK) cells Fang, et al. [2]

\section{Food Antioxidant and Acrylamide Synthesis in Food}

Antioxidants are exogenous, or endogenous molecules. Such molecules neutralize the oxidative damage done by oxidants by their own mechanisms of intra-and extracellular defense. The mechanisms of extracellular defense involve various molecules, such as albumin, bilirubin, transferrin, ceruloplasmine, uric acid, ascorbate, and $\alpha$-tocopherol. The key antioxidant defense mechanism includes intracellular free radical-scavenging enzymes. These enzymes include SOD, GST, GPx, GR, catalase, and cytochrome oxidase Altan et al. [55] Recently various studies showed that antioxidant play an important role in either the prevention and cure of many diseases, the reduction of chemicals-induced toxicity or environmental factors Ibrahim et al. [56,57].

It has been documented that plants with high polyphenol and antioxidant activity such as Theobroma cacao, Solanum nigrum, Panax ginseng, Digera muricata, Crocus sativus, Glycine max and Zingiber officinal and antioxidant compounds such as myrcitrin, genistein and curcumin are effective in reducing ACR toxicity in cell lines and animal studies Zhang et al. [19]. Accordingly, these studies have shown that inhibition of ROS formation, reduction of oxidative stress, increase of GSH and reduction of cell apoptosis are generally proposed mechanisms for phytoconstituents against ACR-induced toxicity Kahkeshani et al. [58] The correlation between phytochemicals with antioxidants and acrylamide can be viewed from two points of view. The former describes antioxidants as exogenous additives, the latter finding them to be secondary endogenous metabolites Ibrahim et al. [56] While some studies about the beneficial effect of curcumin as a potent antioxidant to minimize the formation of ACR, a recent study found that it would promote the growth of ACR.

This is due to the carbonyl moieties, which end up producing acrylamide with aspargine reaction. On the other hand, naringenin with low antioxidant activity react strongly in the Maillard reaction with the amide group of intermediates and block the formation of acrylamide Constantinou et al. [59] In addition, there are several other parameters influencing the production of acrylamide in food including reaction state, solubility, concentration and antioxidant preparation methods, which may confusingly lead to opposite results for the same kind of agent Jin et al. [60]. The negative association between the formation of ACR and the antioxidant composition of food natural raw source Evers et al. [61] The content of acrylamide in fried potato has a negative relation to the raw material's total phenolic content $(-0.367)$ and chlorogenic acid content $(-0.359)$. The presence of excess sugar may however obstruct this beneficial effect Kalita et al. [62] A few studies have focused on classes of phytochemicals other than naturally occurring phenolics such as sulfur or nitrogen. Reduction of ACR content by garlic is due to presence of sulfur containing compounds like alliin and allicin Jin et al. [60]. In addition, piperine, a nitrogen compound also decreases the quantity of acrylamide in the aspargine / glucose model system Zhu et al. [63]

\section{Conclusion and Recommendation}

It could be concluded the toxic effect of acrylamed that may be appeared as neurotoxicity, immunetoxicity, genotoxicity and reproductive toxicity. Acrylamide toxicity may be induced by the disturbance in antioxidants system or induction of cell apoptosis. The antioxidant substances could be beneficial for decreasing the rat of acrylamid synthesis in food during processing. It is recommended that, decreasing of consumption of processed food rich in carbohydrates especially for children and elderly. The addition of antioxidant substances to food during processing. Farther studies are needed to investigate the molecular mechanisms of acrylamide toxicity.

\section{References}

1. Zamani E, Shokrzadeh M, Fallah M, Shaki F (2017) A review of acrylamide toxicity and its mechanism. Pharm Biomed Res 3(1): 1-7.

2. Fang J, Liang CL, Jia XD, Li N (2014) Immunotoxicity of acrylamide in female BALB/c mice. Biomedical and Environmental Sciences 27: 401409 .

3. Taeymans D, Wood J, Ashby P, Blank I, Studer A, et al. (2004) A review of acrylamide: an industry perspective on research, analysis, formation, and control. Critical Reviews in Food Science and Nutrition 44(5): 323 347.

4. Granath F, Ehrenberg L, Paulsson B, Törnqvist M (2001) Cancer risk from exposure to occupational acrylamide. Occupational and environmental medicine 58: 608-660.

5. Pingot D, Pyrzanowski K, Michałowicz J, Bukowska B (2013) Toxicity of acrylamide and its metabolite-glicydamide. Medycynapracy, 64(2): 259271.

6. Tareke E, Rydberg P, Karlsson P, Eriksson S, Törnqvist M, et al. (2002) Analysis of acrylamide, a carcinogen formed in heated foodstuffs. Journal of agricultural and food chemistry 50(17): 4998-5006.

7. Zhang Y, Zhang G, Zhang Y (2005) Occurrence and analytical methods of acrylamide in heat-treated foods: Review and recent developments. Journal of Chromatography A 1075(1): 1-21. 
8. Alberts B, Johnson A, Lewis J, Walter P, Raff M, et al. (2002) Molecular Biology of the Cell. 4th Edition: (New York: Garland Science). Ann Bot 91: 401.

9. Lo Pachin RM (2005) Acrylamide neurotoxicity: neurological, morhological and molecular endpoints in animal models. Chemistry and safety of acrylamide in food 561: 21-37.

10. Rice JM (2005) The carcinogenicity of acrylamide. Mutation Research/ Genetic Toxicology and Environmental Mutagenesis 580(1): 3-20.

11. Shipp A, Lawrence G, Gentry R, McDonald T, Bartow H, et al. (2006) Acrylamide: review of toxicity data and dose-response analyses for cancer and noncancer effects. Critical reviews in toxicology 36(6): 481608.

12. Schettgen T, Rossbach B, Kütting B, Letzel S, Drexler H, et al. (2004) Determination of haemoglobin adducts of acrylamide and glycidamide in smoking and non-smoking persons of the general population. International journal of hygiene and environmental health 207: 531539.

13. Front Matter (2014) Nomenclature of Organic Chemistry: IUPAC Recommendations and Preferred Names 2013 (Blue Book). Cambridge: The Royal Society of Chemistry 842 .

14. Hawley GG, Lewis RJ (1997) Hawley's condensed chemical dictionary. Van Nostr and Reinhold.

15. Kumar J, Das S, Teoh SL (2018) Dietary Acrylamide and the Risks of Developing Cancer: Facts to Ponder. Frontiers in nutrition 5: 14.

16. Ankaiah R, Kurrey NK, Krishnan MH (2018) The positive intervention effects of resveratrol on acrylamide -induced cyto-/Genotoxicity in primary lymphocytes of rat. Pharmacognosy Magazine 14: 643-648.

17. Claus A, Carle R, Schieber A (2008) Acrylamide in cereal products: A review. Journal of Cereal Science 47: 118-133.

18. Krishnakumar T, Visvanathan R (2014) Acrylamide in Food Products: A Review Journal of Food Processing and Technology 5: 7.

19. Zhang Y, Zhang Y (2007) Study on reduction of acrylamide in fried bread sticks by addition of antioxidant of bamboo leaves and extract of green tea. Asia Pacific Journal of Clinical Nutrition 16: 131-136.

20. Negoita M, Culetu A (2016) Application of an accurate and validated method for identification and quantification of acrylamide in bread, biscuits and other bakery products using GC-MS/MS system. Journal of the Brazilian Chemical Society 27: 1782-1791.

21. Dybing E, Farmer PB, Andersen M, Fennell TR, Lalljie SP, et al. (2005) Human exposure and internal dose assessments of acrylamide in food. Food and Chemical Toxicology 43(3): 365-410.

22. Petersen BJ, Tran N (2005) Exposure to acrylamide. Chemistry and Safety of Acrylamide in Food 561: 63-76.

23. Svensson K, Abramsson L, Becker W, Glynn A, Hellenäs KE, et al. (2003) Dietary intake of acrylamide in Sweden. Food and chemical Toxicology 41: 1581-1586.

24. Dybing E, Sanner T (2003) Risk assessment of acrylamide in foods. Toxicological Sciences 75: 7-15.

25. Arisseto AP, De Figueiredo Toledo MC, Govaert Y, van Loco J, Fraselle $S$, et al. (2009) Contribution of selected foods to acrylamide intake by a population of Brazilian adolescent's food. LWT-Food Science and Technology 42: 207-211.

26. Matoso V, Bargi Souza P, Ivanski F, Romano MA, Romano RM, et al. (2019) Acrylamide: A review about its toxic effects in the light of Developmental Origin of Health and Disease (DOHaD) concept. Food Chemistry 283: 422-430.

27. Sumner SC, Fennell TR, Moore TA, Chanas B, Gonzalez F, et al. (1999) Role of cytochrome P450 2E1 in the metabolism of acrylamide and acrylonitrile in mice. Chemical in Research in Toxicology. 12:1110-1116.
28. Riboldi BP, Vinhas ÁM, Moreira JD (2014) Risks of dietary acrylamide exposure: A systematic review. Food Chemistry 157: 310-322.

29. Bucur M, Bucur B, Radu G (2018) Simple, selective and fast detection of acrylamide based on glutathione S-transferase. RSC Adv 8: 2393123936.

30. Zhao M, Wang F, Hu X, Chen F, Chan M (2017) Effect of acrylamideinduced neurotoxicity in a primary astrocytes/microglial co-culture model. Toxicology in Vitro 39: 119-125.

31. Mojtahedzadeh M, Ahmadi A, Mahmoodpoor A, Beigmohammadi MT, Abdollahi M, et al. (2014) Hypertonic saline solution reduces the oxidative stress responses in traumatic brain injury patients. Journal of Research in Medical Sciences 19: 867- 874

32. Shaki F, Hosseini MJ, Ghazi Khansari M, Pourahmad J (2012) Toxicity of depleted uranium on isolated rat kidney mitochondria. Biochimica et Biophysica Acta (BBA)-General Subjects 1820: 1940-1950.

33. Chen W, Shen Y, Su H, Zheng X (2014) Hispidin derived from Phellinus linteus affords protection againstacrylamide-induced oxidative stress in Caco-2 cells. Chemico- Biological Interactions 219: 83-89.

34. Yilmaz BO, Yildizbayrak N, Aydin Y, Erkan M (2017) Evidence of acrylamide- and glycidamide-induced oxidative stress and apoptosis in Leydig and Sertoli cells. Humanand Experimental Toxicology 36: 12251235.

35. Naruszewicz M, Zapolska Downar D, Kośmider A, Nowicka G, Kozłowska Wojciechowska M, et al. (2009) Chronic intake of potato chips in humans increases the production of reactive oxygen radicals by leukocytes and increases plasma C-reactive protein: a pilot study. The American Journal of Clinical Nutrition 89: 773-777.

36. Nakagawa Y, Choi D, Ogane N, Shimada S, Seya M, et al. (2001) Discovery of a novel compound: insight into mechanisms for acrylamide-induced axonopathy and colchicine-induced apoptotic neuronal cell death. Brain Research 909: 8-19.

37. Valko M, Leibfritz D, Moncol J, Cronin MT, Mazur M, et al. (2007) Free radicals and antioxidants in normal physiological functions and human disease. The International Journal of Biochemistry and Cell Biology 39: 44-84.

38. Rodríguez Ramiro I, Ramos S, Bravo L, Goya L, Martín MÁ, et al. (2011) Procyanidin B2 and a cocoa polyphenolic extract inhibit acrylamideinduced apoptosis in human Caco-2 cells by preventing oxidative stress and activation of JNK pathway. The Journal of Nutritional Biochemistry 22: 1186-1194

39. Li S, Cui N, Zhang C, Zhao X, Yu S, et al. (2006) Effect of subchronic exposure to acrylamide induced on the expression of bcl-2, bax and caspase-3 in the rat nervous system. Toxicology 217: 46-53.

40. Chen JH, Chou CC (2015) Acrylamide inhibits cellular differentiation of human neuroblastoma and glioblastoma cells. Food and Chemical Toxicology 82: 27-35.

41. Okuno T, Matsuoka M, Sumizawa T, Igisu H (2006) Involvement of the extracellular signal-regulated protein kinase pathway in phosphorylation of p53 protein and exerting cytotoxicity in human neuroblastoma cells exposed to acrylamide. Archives of Toxicology 80: 146-153.

42. Morrison RS, Kinoshita Y, Johnson MD, Guo W, Garden GA, et al. (2003) p53-dependent cell death signaling in neurons. Neurochemical Research 28: $15-27$.

43. Sumizawa T, Igisu H (2007) Apoptosis induced by acrylamide in SHSY5Y cells. Archives Toxicolology 81: 279-282.

44. Liu Z, Song G, Zou C, Liu G, Wu W, et al. (2015) Acrylamide induces mitochondrial dysfunction and apoptosis in BV-2 microglial cells. Free Radical Biology Medicine 84: 42-53.

45. Exon J (2006) A review of the toxicology of acrylamide. Journal of Toxicologyand Environmental Health Part B 9: 397-412. 
46. Lo Pachin RM (2004) The changing view of acrylamide neurotoxicity. Neuro Toxicology 25: 617-630.

47. Hagmar L, Törnqvist M, Nordander C, Rosén I, Bruze M, et al. (2001) Health effects of occupational exposure to acrylamide using hemoglobin adducts as biomarkers of internal dose. Scandinavian Journal of Work, Environment \& Health 27: 219-226.

48. Pelucchi C, Galeone C, Levi F, Negri E, Franceschi S, et al. (2006) Dietary acrylamide and human cancer. International Journal of Cancer 118: 467471.

49. Pelucchi C, Rosato V, Bracci PM, Li D, Neale RE, et al. (2017) Dietary acrylamide and the risk of pancreatic cancer in the International Pancreatic Cancer Case-Control Consortium (PanC4). Annals of Oncology 28: 408-414.

50. Hogervorst JG, Schouten LJ, Konings EJ, Goldbohm RA, Van Den Brandt PA (2008) Dietary acrylamide intake and the risk of renal cell, bladder and prostate cancer. The American Journal of Clinical Nutrition 87: 1428-1438.

51. Alzahrani HAS (2011) Protective effect of l-carnitine against acrylamideinduced DNA damage in somatic and germ cells of mice. Saudi Journal of Biological Sciences 18: 29-36.

52. Tyl RW, Friedman MA (2003) Effects of acrylamide on rodent reproductive performance. Reproductive Toxicology 17: 1-13.

53. Wang H, Huang P, Lie T, Li J, Hutz RJ, et al. (2010) Reproductive toxicity of acrylamide-treated male rats. Reproductive Toxicology 29: 225-230.

54. Wei Q, Li J, Li X, Zhang L, Shi F, et al. (2014) Reproductive toxicity in acrylamide-treated female mice. Reproductive Toxicology 46: 121-128.

55. Altan N, Dincel AS, Koca C (2006) Diabetes mellitus ve oxidative stress. Turkish Journal of Biochemistry 31: 51-56.

ISSN: 2574-1241

DOI: 10.26717/BJSTR.2020.27.004480

Mohamed Afifi. Biomed J Sci \& Tech Res

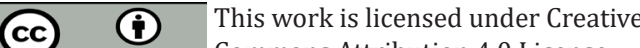
Commons Attribution 4.0 License

Submission Link: https://biomedres.us/submit-manuscript.php
56. Ibrahim R, Nawar I, Yousef M, El Sayed M, Hassanein A, et al. (2019) Review Article, Protective Role of Natural Antioxidants Against the Formation, and Harmful Effects of Acrylamide in Food. Trends in Applied Sciences Research 14: 41-55.

57. Banu 0 (2019) Protective effects of vitamin C and curcumin against acrylamide toxicity in embryonic fibroblast cells. Toxicological \& Environmental Chemistry 101: 389-403.

58. Kahkeshani N, Saeidnia S, Abdollahi M (2015) Role of antioxidants and phytochemicals on acrylamide mitigation from food and reducing its toxicity. Journal of Food Science and Technology 52: 3169-3186.

59. Constantinou C, Koutsidis G (2016) Investigations on the effect of antioxidant type and concentration and model system matrix on acrylamide formation in model Maillard reaction systems. Food Chemistry 197: 769-775.

60. Jin C, Wu X, Zhang Y (2013) Relationship between antioxidants and acrylamide formation: a review. Food Research International 51: 611620.

61. Evers D, Deuber H (2012) Potato antioxidant compounds: Impact of cultivation methods and relevance for diet and health, nutrition, wellbeing and health, In: Bouayed J (Eds.)., Nutrition, InTech.

62. Kalita D, Holm DG, Jayanty SS (2013) Role of polyphenols in acrylamide formation in the fried products of potato tubers with colored flesh. Food Research International 54(1): 753-759.

63. Zhu F, Cai YZ, Keb J, Corkea H (2009) Evaluation of the effect of plant extracts and phenolic compounds on reduction of acrylamide in an asparagine/glucose model system by RP-HPLC-DAD. Journal of the Science Food and Agriculture 89: 1674-1681.

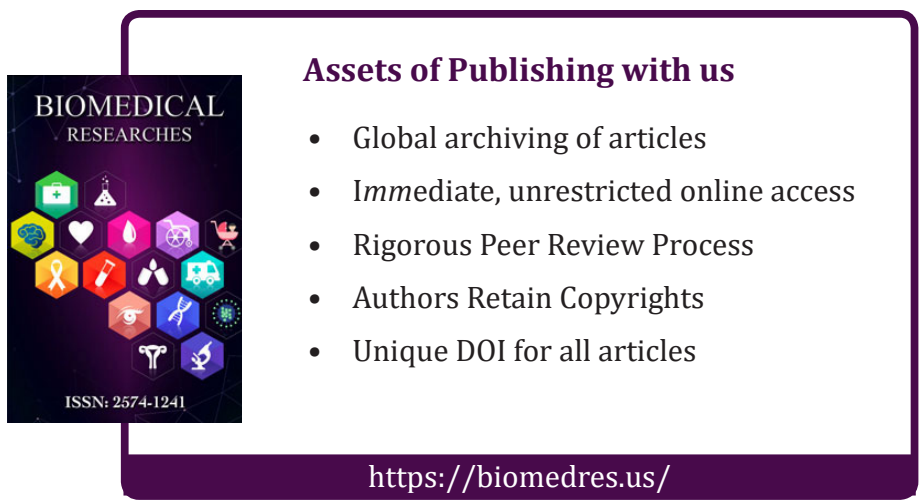

